\title{
Caregiving at Night: Understanding the impact on carers
}

\author{
Sara Arber ${ }^{1}$ and Susan Venn ${ }^{2}$ \\ 1. Centre for Research on Gender and Ageing (CRAG), \\ Department of Sociology, \\ University of Surrey, \\ Guildford GU2 7XH, UK \\ Telephone: 00-44-1483 686936 \\ Fax: 00-44-1483-689551 \\ Email: S.Arber@surrey.ac.uk \\ 2. Centre for Research on Gender and Ageing (CRAG), \\ Department of Sociology, \\ University of Surrey, \\ Guildford GU2 7XH, UK \\ Telephone: 00-44-1483 68?? \\ Fax: 00-44-1483-689551 \\ Email: S.Venn@surrey.ac.uk \\ Corresponding Author \\ Sara Arber
}

Submitted to the Journal of Aging Studies, February 2010 


\title{
Caregiving at Night: Understanding the impact on carers
}

\author{
Abstract \\ Caregiving research has rarely examined the nature and impact of care provision at night. \\ This paper, based on indepth interviews with older people with poor sleep in England, \\ examines how caregiving at night influences carers' sleep. A proposed framework illustrates \\ how six aspects of caregiving can disrupt carers' sleep quality: first, attending to the night- \\ time physical needs of the person cared for; second, anticipation of their night-time care \\ needs; third, 'monitoring' their relative at night; fourth, disruption from relatives awake for \\ long periods at night, wandering or shouting; fifth, undertaking emotional support, and \\ worries or anxieties related to their relative; and finally, the legacy of caregiving may \\ continue to disrupt sleep after caring ceases, because of painful images of their relative's \\ suffering or feelings of guilt. Adverse effects on carers' sleep are greatest for co-resident \\ carers, especially when caring for a spouse with a life-limiting illness or dementia.
}

Keywords: Night-time, carers, caregiving, sleep, older people, England 


\section{Introduction}

Although extensive literature has documented the diverse ways that caregiving impacts on the lives of carers, little research has examined the ways that carers manage the nighttime and how care provision may influence their own sleep. This is surprising since coresident caregiving occurs on a 24 hour basis and many disabled/frail older people suffer from health conditions that adversely affect their sleep. This paper proposes a framework to illustrate the various ways that caregiving at night can influence the sleep of carers.

\section{Researching daytime and night-time caregiving}

Research on caregiving roles has adopted two main approaches. Firstly, a time-based approach measures the duration of time spent in assisting or helping the care recipient, usually based on number of hours per week (Maher \& Green, 2002; Dahlberg, Demack \& Bambra, 2007). Second, a task-based approach measures whether the carer undertakes tasks associated with Activities of Daily Living (ADLs) (e.g., dressing, bathing, helping with toileting, eating, and medication use), and/or Instrumental Activities of Daily Living (IADLs) (e.g., shopping, cooking, household cleaning, laundry, transportation, financial management and home maintenance) (Lawrence et al., 2002). 'Time-based' and 'taskbased' approaches both characterize the caregiving role as one of largely 'doing' care for the older person, with care measurable as time or provision of tasks or activities.

A time-based approach often categorizes the highest weekly time interval of caregiving as 20 or more hours (Ross et al., 2008) or has a maximum threshold of over 50 hours 
(Dahlberg, Demack, \& Bambra, 2007). However, only where caregiving is categorized as over 100 hours per week, is it obvious that this includes care provision at night. The UK Carers 2000 survey showed that the number of hours spent caring was strongly associated with disturbed sleep. Almost half of carers providing 50 hours or more of care each week (47\%) reported disturbed sleep, compared with a quarter (24\%) caring for 2049 hours, and only 7\% among carers providing under 20 hours per week (Maher \& Green, 2002).

A task-based approach will tend to omit night-time care provision, since neither IADLs nor ADLs are conventionally undertaken at night. However, ADLs may need to be performed at night, for example, helping a relative go to the toilet, or washing their relative (and/or changing their bed) following night-time incontinence. Although, personal and intimate caring tasks may be undertaken at night, as well as tasks such as medication administration, studies measuring ADLs usually only ask whether ADLs are performed or their frequency of performance, not when they are performed.

Sleep disturbance may also relate to other aspects of night-time caregiving. James (1992) introduced a three-fold classification of care provision as 'physical labour' (ADL and IADL tasks), 'emotional labour' and 'managerial or organizational labour'. 'Emotional labour' or emotional support is harder to measure than 'physical labour'. It encompasses thinking about, being alert to and recognizing the needs and wants of others, which Mason (1996) termed 'sentient activity'. Studies rarely distinguish the emotional support provided when caring for older people during the night. It is well-known that worries 
disrupt sleep, and worries about relatives in need of care are likely to affect sleep quality. Women are particularly likely to report that 'family worries' disturb their sleep (Arber $e t$ al., 2007), and 'worries' are a larger predictor of women's than men's sleep problems (Arber, Bote, \& Meadows, 2009).

The managerial or organizational labour involved in caregiving is largely invisible and receives less attention in caregiving research (Rosenthal, Martin-Matthews, \& Keefe, 2007). It often involves spending time co-ordinating care provision by other informal caregivers and a range of formal care providers (Sims-Gould, Martin-Matthews, \& Rosenthal, 2008). Although, such managerial care does not occur at night and would not directly disrupt caregivers' sleep, the anxieties and worries associated with this managerial care role may disturb sleep. Rosenthal et al. (2007: 774) found that 'The orchestration of care... is the aspect of managerial care that was associated with personal and job costs, and that among women it contributed to stress.'

The night-time activities or behaviours of the person being cared for may disturb carers' sleep, e.g. wandering or yelling. Different types of night-time disturbances are likely to engender varying levels of stress/anxiety, and influence the ease with which carers can return to sleep following the disruption (Beaudreau et al., 2008). A care recipient needing help to use the toilet might represent a 'relatively benign' disruption, compared to being woken because of wandering or yelling, which may be more stressful for the carer. 
Some older care recipients may be considered 'at risk' or in danger to themselves at night, requiring the carer to be involved in 'surveillance', 'monitoring' or 'maintaining night-time vigilance', particularly a person with dementia or with a lifethreatening/terminal illness. Askham and colleagues' qualitative study of 20 carers for persons with dementia illustrates that carers' perceived the need to undertake surveillance at night, which was problematic to all carers, including preventing carers 'getting a good night's sleep' (2007: 13). The temporal duration and patterning of 'surveillance' or 'monitoring' by carers is largely invisible and has rarely been examined in caregiving research, yet may adversely affect carers' sleep. Monitoring involves an 'invisible provisioning activity' that is linked to 'ensuring safety' (Neysmith \& Reitsma-Street, 2009).

The extensive literature on the burdens of caregiving has documented the ways that the carers' life is constrained and their quality of life reduced (Zarit, Reever, \& BachPeterson, 1980; Ross et al., 2008). Caregiving is associated with stress, reduced psychological well-being and higher levels of depression among caregivers (Keene \&and Prokos, 2008; Cannuscio et al., 2002; Hirst, 2005). However, it has rarely been considered whether the link between caregiving and distress/depression is partly through the mechanism of poor sleep, with sleep disruption acting as an intermediary factor between aspects of night-time caregiving roles and elevated levels of carers' depression/distress.

\section{Researching sleep and caregiving}


Sleep is a routine (nightly) activity, which generally goes unremarked and unacknowledged (Williams, 2005). There are several reasons for studying caregiving at night and how it might affect carers' sleep. First, lack of sleep leads to daytime fatigue and reduces the carers' quality of life (Riedel \& Lichstein, 2000; Ross et al., 2008). Second, lack of sleep results in tiredness and low mood/bad temper, which may reduce carers' ability to provide high quality, emotionally supportive care to their relative. Third, sleep problems are a major predictor of subsequent entry into nursing homes (Pollak \& Perlick, 1991; Kesselring et al., 2001). Pollak and Perlick (1991) found that $70 \%$ of primary caregivers of elders recently admitted to US nursing homes cited nocturnal problems in their decision to institutionalize, primarily because their own sleep was disrupted.

Finally, sleep scientists have shown that sleep is important for both physical and mental health. Long-term sleep loss has been linked to impaired glucose metabolism and decreased immune function (Speigel, Ellgring, \& Oertel, 1999) with prospective studies finding that short sleep duration (under 6.5 hours) is associated with higher mortality (Heslop et al., 2002; Ferrie et al., 2007), and increased risk of diabetes and coronary heart disease (Ayas et al., 2003). Individuals suffering from depression and anxiety have poor sleep, with prospective studies demonstrating that sleep problems often predate onset of depression and anxiety (Ustun, 2000; Hartz et al., 2007).

Chronic ill-health often causes pain and discomfort at night, resulting in poor sleep quality (Davidson et al., 2002; Vitiello, Moe, \& Prinz, 2002; Happe \& Berger, 2002), and 
dementia leads to altered circadian rhythms and a weaker diurnal pattern, including broken night-time sleep (Bliwise, 1993; Van Someren, 2000; Lee, Morgan, \& Lindesay, 2007). Therefore, chronic illness, physical disability and cognitive impairment not only directly impacts on the older person's sleep quality, but also potentially disrupts carers' sleep.

The few research studies that have specifically focused on caregiving and sleep have mainly been conducted by medical researchers. Most are 'disease-specific', based on clinical samples of patients with particular health conditions, such as cancer or Parkinson's disease (Smith, Ellgring, \& Oertel, 1997; Carter \& Chang, 2000; Happe \& Berger, 2002), or dementia (Willcox \& King, 1999; Lee et al., 2007; Beaudreau et al., 2008; Creese et al., 2006). These studies on patients with specific conditions use a medical framework, and have documented the extent of sleep disruption for carergivers. However, they provide little conceptual understanding of how various aspects of care provision at night might adversely affect carers' sleep or the meanings and perceptions of carers about managing the night-time.

Bianchera and Arber's (2007) qualitative research on midlife and older women in Italy (age 40-80) showed how caregiving at different stages of women's life course influenced their sleep. They proposed a four-fold typology of the effects on Italian women's sleep which identified (1) provision of night-time care for direct (physical) needs, (2) anticipation of having to undertake care tasks at night, (3) worries at night related to caregiving, and (4) long-term consequences related to the 'legacy of caregiving'. Their 
typology was constructed from data on how caring at night for young children, teenage/adult children, and elderly relatives affected Italian midlife and older women's sleep. Their study only related to women and to the specific cultural and welfare context of Italy. Therefore, it is pertinent to assess its applicability in other societal contexts and for men, as well as women, caregivers.

This paper aims to:

1. Provide insights into the ways that carers manage the night-time, and to what extent caregiving disturbs their sleep.

2. Assess the appropriateness of Bianchera and Arber's (2007) typology for understanding the impact on older women and men of providing night-time care for a partner or other relative in England.

\section{Methods}

Data collection was undertaken in two parts. Part one comprised a self-completion questionnaire of 2400 people aged 65+ sent out through 10 general practices in South East England in 2008. The questionnaire comprised a modified Pittsburgh Sleep Quality Index (PSQI) (Buysse et al., 1989) and basic socio-demographic questions such as marital status and employment. From those who returned the questionnaire $(n=1158)$, and indicated they were willing to take part in further studies, 62 men and women aged between 65 and 95 , with a score of $>5$ on the PSQI, (an indicator of clinically poor sleep) 
were invited for part 2 of data collection in the form of an interview. In-depth semistructured interviews were conducted (by SV) in the respondents' own homes and lasted between 1 and 3 hours. Those who consented to have extracts of their interviews appear on the Healthtalkonline website (www.healthtalkonline.org) as a module called 'Sleep Problems in Later Life' were video and/or audio recorded $(n=39)$ and all other interviews were audio recorded.

The qualitative interviews focused on the range of social factors which affected the participants' sleep, the meanings and experiences of poor sleep, and how they dealt with any sleep difficulties (see Appendix A: Interview Topic Guide). Participants were also asked how their sleep had changed across their life course, including any effects of their own ill-health, and ill-health of a partner or other relatives. The interview was not specifically designed to examine how caregiving at night influenced their sleep, but during other projects conducted by the authors on sleep (Negotiating Sleep: Gender, Age and Social Relations Amongst Couples, ESRC-funded: 2003-2006, Sleep in Ageing Women, EU-funded,: 2001-2004) and piloting of the interview guide, caring emerged as a key theme and was therefore included as a topic in all interviews. Of the 62 respondents who were interviewed, 23 had, or were currently involved, in caring for a close family member(s) and a further two had experienced caregiving and the impact of caregiving on their sleep through their employment. The study received approval from the NHS (MREC) and University of Surrey Ethics Committees. 
The interviews were analysed using a thematic analysis approach (Miles \& Huberman, 1994) allowing concepts to emerge directly from the data. The transcripts were systematically re-read to identify relevant analytic themes and examine relationships between the categories, comparing and contrasting findings from the interviews. A subsample of the interviews was also read by a Senior Researcher from the Healthalkonline group at the University of Oxford to check for coding errors or omissions. The software package, NVivo 8.0, was used to support thematic analysis by identifying emerging themes, which were later expanded, clarified and grouped under broader categories and concepts such as caring, attitudes to daytime sleep and ageing identity. Pseudonyms are used to protect the anonymity of respondents, with their age indicated after quotations. Table 1 illustrates the characteristics of those who have been, or were currently involved in caring for a family member, including gender, age of carer, relationship to person being cared for, location of caregiving, and reasons for caring. Apart from the two cases where caring was undertaken within a work context, all relationships were either lifelong (as in parental or sibling) or long-term, as in a spouse or parent-in-law and caregiving ranged from several weeks to more than ten years. A history of the respondents' sleep patterns and experiences was also taken as part of the interview.

$<$ Insert Table 1 about here $>$

\section{Aspects of caregiving at night}


Of the respondents interviewed, $40 \%$ provided accounts of caregiving at night, the majority of which related to care for their spouse or parent. Analysis of the data led to refining and extending the preliminary four-fold typology based on Italian women (Bianchera \& Arber, 2007) into six conceptually distinct 'aspects of night-time caregiving' that can affect carers' sleep, see Chart 1. Our analysis of English data provides a fuller understanding of how four previously identified aspects affect the sleep of both older men and women who provide care for their partners and other relatives. In addition, two further aspects were identified from the English data, which were 'monitoring and surveillance' and 'disruptive night-time behaviours of the care recipient'.

The framework in Chart 1 proposes six conceptually distinct ways in which caregiving at night may influence the carers' own sleep and well-being, however, in most cases our research showed that their night-time was disrupted by a combination of these aspects. We illustrate that in different types (or stages) of illness, some aspects of night-time caregiving are more likely than others to contribute to sleep disturbance. The location of caregiving, sleeping arrangements, types of illness and gender are associated with whether carers undertake these different aspects of night-time care.

$<$ Insert Chart 1 about here $>$

Co-resident caregiving, especially for a relative with life-limiting illness or dementia, often resulted in all or most of these aspects adversely affecting carers' sleep. This 
particularly occurred during lengthy periods of spouse care with carers' sleep generally disrupted by the first three 'aspects of caregiving', namely 'providing physical care at night', the 'anticipation of having to provide care at night' and 'monitoring and surveillance'. Dementia care had a major influence on sleep disruption, especially from the fourth aspect: disturbance through 'night-time behaviours of care recipient'.

Although, a carers' night-time is likely to be disturbed by more than one of these aspects of night-time caregiving, for heuristic reasons we discuss each aspect separately.

\section{Providing direct physical care at night}

During the day, co-resident caregivers of a person with severe ill-health or terminal illness may receive support from domiciliary care services or paid carers, such as to get them into and out of bed or to dress wounds. They may also receive daytime assistance from other family members, such as daughters who live nearby. However, co-resident carers generally have to provide all necessary care or support to their relative during the night themselves. The interviews revealed how intensive caregiving for spouses, often for several years, severely disrupted the carers' sleep.

Ray had nursed his terminally ill wife with cancer (for 3 years) until 2 days before she died. Although, care assistance was received during the day from carers and a nurse, his nights were severely disturbed by several aspects of caregiving.

Six times a night I would get up to go (with wife) to the toilet, and waking, waking all the rest of the time. And, in fact, when we got that (type II diabetes) under 
control, it would probably go down to three times a night. And then it went up again after Christmas. It was only two or three times a night, but each time would take half an hour literally to get her up there, or to get her onto the commode, and so I used to dread nights.... I used to absolutely dread nights and in retrospect I can see how I was sailing close to the limit of my own endurance... (Ray, 76)

As the sole caregiver for his wife at night, Ray found providing care at night was much more problematic than during the day. Doug also received a lot of support during the day to help care for his wife who had a severe stroke and lived at home for 6 years before she died. His wife had received morning and evening domiciliary support from paid carers, as well as help from their two daughters living nearby, and their grandson. Doug was her main caregiver at night, and in the earlier stages, following her stroke, they slept in a bedroom upstairs, but the bathroom was downstairs, Doug said:

When she was ill and upstairs, I used to carry her up and down stairs to the toilet and when she got really bad, then she had to have a commode in here, and, oh, it was horrible... (Doug, 67)

Doug's sleep was severely compromised by caring for his wife at night. Many co-resident carers were solely responsible for extensive direct physical care at night, which contrasted with their receipt of domiciliary and other care support services during the daytime. The sleep of many spouse carers was particularly affected, especially those who 
were heavily involved in caring for their spouse for many years, including during the terminal phase of illness.

The impact on carers' sleep of providing direct physical care at night depends on the severity of the illness and the frequency of awakenings to address the needs of the person cared for, as well as the carers' ability to fall asleep again rapidly afterwards. The latter is affected by many of the other aspects of caregiving that will now be discussed.

\section{Anticipation of providing physical care at night}

The anticipation of having to provide physical care at night may be as disruptive to carers' sleep as the actual provision of care. Thus, carers' sleep was usually disrupted both by responding to the need itself, and by the anticipation of having to provide care. This anticipation resulted in light and 'alert' sleep, which took the place of restful, deep and restorative sleep. Ray recounted how he remained alert throughout the night.

I was like a sentry on guard and she (wife) would initially try and get out of bed and not wake me up, but then she couldn't get out of bed, so any slight disturbance, I was awake and active... I was like on duty for virtually 24 hours a day. (Ray, 76)

The anticipation of being 'called' at night also occurs for non-resident caregivers. In England, adult children often provide care during the day to elderly/frail parents who live alone. However, even those caring 'at a distance', may still have their sleep disrupted by the anticipation of being 'called' during the night or by actually being called out at night, 
as well as by worries and anxieties (aspect 5) and the 'legacy of caregiving' (aspect 6). Many frail older people who live alone have a care alarm system installed in their home, which is connected to a 24 hour care service. If the older person activates the care alarm, the care service telephones their relative, who has to visit to address the problem, irrespective of the time of day or night. Therefore, even though an older relative may live alone, their carergivers' sleep may be disrupted by either the anticipation of 'being called out' or actual phone calls from the care service or the care recipient themselves.

She (mother) lived in her little bungalow... it did get a bit disturbing, because if she had fallen, and she had pressed that button, and then they would call you out... Or she used to ring and say the carer hadn't been, because she had carers, you know, to get her up and put her to bed... but they didn't always turn up, so when they didn't turn up, she used to ring me... You weren't sleeping well, because you were thinking that you might get called out' (Ann, 71)

Older people, particularly with dementia, who live alone or in a residential facility, may telephone their relatives at any time of the day or night with queries or concerns, thereby disturbing their relatives' sleep. Anita provided care for many years for her mother who lived nearby:

Anita When she (mother) was in her flat, as she got older, she was turned 90 when she died, and she'd had lots of falls and breaks and illnesses. So we were back and forth... She wouldn't hesitate to have me go out, if she wanted anything... 
Jeff (Anita's husband). On occasions she would phone here late at night or early in the morning, and the best example is where she phoned up, and when we woke up and lifted the phone, she said '[Anita] what time is it'? And [Anita] said 'It's 2 o'clock in the morning, Mother'. And she said 'Oh, that's the same time as my clock'. (Anita, 79)

For non-resident caregivers, the anticipation that their relative or the care services may telephone them during the night created anxiety and reduced their likelihood of deep restorative sleep. However, co-resident carers experienced comparatively greater adverse effects on their sleep due to 'anticipation' of having to deal with the care recipients' needs at night.

\section{Monitoring and surveillance}

Care homes have policies that care staff routinely check on residents during the night, because of the risk that a resident may have fallen out of bed or be unwell, or to change their incontinence pad. There may be parallel issues for older/disabled people receiving care at home, in terms of whether they are or should be checked or monitored regularly at night by their co-resident carer. If regular night-time monitoring is undertaken, this will adversely affect the quality and duration of the carers' sleep. As illustrated earlier, Ray, who cared for his wife with cancer for 3 years, described himself as 'like a sentry on guard'. 
The nature of monitoring by caregivers takes many forms, and may be conducted in a subtle way, showing an empathetic concern for the well-being of the care recipient. Caregivers may perform this night-time monitoring sensitively, in order not to wake the care recipient, or not make it too obvious that they are 'checking up' on them. To keep another under monitoring or survelliance could be seen as dehumanizing the care recipient, and treating them as a child. Thus, the caregiver may use emotional skills to perform monitoring in a non-obtrusive and sensitive way.

Ethel's mother had moved to live in an annex built on the side of their house. Caregiving disrupted Ethel's sleep in several ways, including the provision of direct care to her mother at night (aspect 1), the anticipation of being called (by the bell) (aspect 2), as well as monitoring her mother who was often awake for long periods at night:

Well, I had my mother living with me for seven years and she ended up bedridden with arthritis... I used to creep down. Well, I could look through the banisters. She was in that room there. And I had a mirror on her sideboard there, that I could see in the mirror what she was doing. She often used to be reading or knitting in the middle of the night. When I knew the light was on, I used to think to myself, I wouldn't go and disturb her unless. (pause) She had a bell to ring if she needed me, you see, but I wouldn't go in to disturb her... (Ethel, 79) 
John's wife had suffered from severe diabetes for several years, and died 9 months before the interview. His sleep was severely disrupted by different aspects of caregiving, including monitoring his wife regularly while she slept:

John Well, I would go to bed and go to sleep, but I always had light sleeping. I used to have to always keep tapping her... just feeling the back of her neck. If I felt the back of her neck all clammy, then I had to be. (pause) I knew something was going to happen... That was when she was going to have a hypo...

Int. So, in the night you would just constantly be checking her. When you woke up and touched her, could you get back to sleep? Or did it spoil the quality of your sleep?

John Oh no, I couldn't get off. Well I would get off, but it was only a light sleep. I don't know what a good solid sleep is. (John, 67)

As discussed earlier, Doug's sleep had been disrupted by providing physical care and taking his wife (partially paralysed with a stroke) to the toilet during the night. His wife later had to move to a bed downstairs in the living room, and was 'put to bed' and 'got up' on a daily basis by domiciliary carers. After this, Doug's sleep was less disturbed, because his wife was no longer co-present while he slept at night. Doug was asked if he checked on his wife during the night and replied:

(One night) I went to bed around midnight and she was in bed then. And I came down at 7 (next morning) and she was laying on the floor. Now, she could have 
fallen out of bed at 10 past 12 . And she could have laid, no covers on her, she couldn't shout. She couldn't talk, she couldn't get up. So, she just laid there all night, just with her nightie on. Or, she could have fallen out 10 minutes before I came down. Because it was no good asking her 'How long have you been there?' because she couldn't say if she had been there all night. She just wouldn't know. So, maybe I should have come down and checked on her. (Doug, 67)

Thus, Doug was not engaged in monitoring his wife during the night, and his own sleep had improved since his wife was moved to sleep downstairs. If carers perceive the need to check on or 'monitor' their relative during the night, this can lead to carers having broken, alert or light sleep, as well as greater anxieties.

\section{Wandering and disruptive night-time behaviours of the care recipient}

The night-time is generally not a time of quietness and unbroken sleep for people with serious physical disabilities or dementia. Older people themselves often cannot sleep because of pain or needing to use the toilet, which may also disturb their caregiver. Persons with dementia often have disturbed sleep-wake cycles, and as a result are active during the night and asleep or dozing during the day. The night-time wanderings or actions of people with dementia can be problematic for the sleep of carers.

Susan had provided care at home for her father who had a brain tumour and for her mother who had dementia, but found caring for her mother much more difficult: 
They (parents) came to live with us and my father had a brain tumour and my mother had dementia, so it was all quite traumatic... He (father) kept falling out of bed, as well... But my mother was the worst because she had dementia... She, talk about sleep, she wouldn't go to bed until two or three in the morning... She would get up about mid-day, if at all. She didn't like getting up. So, she was quite difficult to look after. (Susan, 72)

Pamela had cared at home at different times for both her parents, and for her husband who had died from 'heart trouble', but she reported that the greatest disruption to her sleep was while caring for her mother who had Alzheimer's:

My father... we were up two or three times a night with him, and then my husband, and I also looked after him, but mummy she had Alzheimer's .... And I thought, 'Well, I can't cope with this'. And then she used to go into bed fine, and then within an hour, she was up again, and then coming in to see what I was doing, sort of thing. So, I think that probably sort of triggered everything off (bad sleeping). Anyway in the end it got so desperate. It is 24 hours a day, I don't care what anybody says, you cannot look after somebody all that length of time. And I went to the doctor and dissolved into tears, and said 'I am sorry, but I just can't go on'. So, he said 'Come on, we have got somewhere now (a local care home)'... She was in there (care home) for 18 months. I didn't want to have to do it, but I just had to. (Pamela, 71) 
Pamela illustrates the stress of 24 hour caregiving for people with dementia, which for the carer is compounded by fatigue induced by lack of sleep, due to the disrupted sleepwake patterns of the person with dementia. In this case, and in other similar cases, lack of sleep precipitated admission to a residential facility (Pollak \& Perlick, 1991).

Residential placement is a normative option for most older parents when it is no longer possible for them to be cared for in their own home, with only a small minority of elderly parents moving to co-reside with their adult children when they need intensive caregiving. However, residential placement is less likely for a husband or wife with dementia or who is terminally-ill (Bond, Clark \& Davies, 2003). Thus, husbands and wives caring for a partner with moderate/severe dementia for long periods at home, may experience substantial sleep disruption, due to their partner's broken sleep-wake patterns.

\section{Emotional labour and the impact of worries about the care recipient}

Caring comprises not only 'caring for' but also 'caring about' family members (Finch \& Groves, 1983). 'Caring about' encompasses the 'emotional labour' of being empathetic about the needs or well-being of other family members (Mason, 1996), as well as having concerns and worries about their 'loved one', which may disturb the carers' sleep.

Edna illustrates empathetic understanding when she senses that her husband is in pain, and attuning to her husband's well-being at night makes the quality of her sleep lighter and more alert: 
He gets this awful pain, stabbing pain in his legs and that... But the point is, I know (recognise) when he is in pain, he moves differently. (Edna, 83)

Caregiving may encompass the provision of emotional support during the night, such as Debora who spent time downstairs supporting her husband (with cancer) at night:

I think it (my sleep) started to change when my husband started to become poorly (he had cancer for 3 years). And he would be awake a lot in the night... We used to go down (and sit in the kitchen)... so we could just stay up all night really... I was just awake and aware of him being awake, and he'd try and creep downstairs sometimes, but you are still aware of it... So, I would come down and join him, and have a little chat, about this and that... (Debora, 73)

Worries and anxieties may create difficulties going to sleep, or returning to sleep if carers are woken (or wake) during the night. Intrusive thoughts and worries about the care recipient may relate to short-term or generalised worries, about the immediate physical and/or emotional well-being of the care recipient, e.g. worrying if they are in pain, or whether they have been incontinent. These types of worries may disrupt the carers' sleep, even if the care recipient is living in a residential facility, as in the following extract:

Joan Unfortunately, my husband has Alzheimer's and I think that is the root of my sleep problems quite frankly... He lives in X Hospital.... And you know there 
is anxiety about him all the time. So, his illness, I think, has probably quite a lot to do with my sleep problems...

Int. How long have you been taking them (sleeping pills)?

Joan Well, I think I must have been taking them for about, well, ever since (husband) has been in the hospital. I think it might be 5 or 6 years. (Joan, 68)

Long-term worries about the future can also adversely affect carers' sleep, for example worries about whether their relative will have to move into a residential facility, will have a painful, anguished death, or whether the carer will manage to cope when their relative becomes progressively more incapacitated. Edna cares for her 87 year old husband who has serious back and mobility problems and great difficulty with stairs. At night, she worries about her husband getting up and down stairs (generalized worries), and whether they will be able to move to a bungalow in the future (long-term worries), where there would be no danger of her husband climbing the stairs.

Eventually you do sleep, and normally, I wake up about 4 o'clock... I think quite possibly that it is because my mind doesn't relax, because with David (husband) and his back and legs, and sometimes he has awful pain in his foot and he can't sleep, and it does worry me that... Oh, I don't go to sleep, I keep tossing and turning. The trouble is, when you don't sleep, all the things that bother you, it is going through your mind, and at the moment, we are hoping to get a bungalow, and it's all this, I hope it won't be long, you know, goes through my (mind). I hope it 
won't be long, because with David... The stairs... when he (David) comes

downstairs, it is just awful to see him. And it just worries me. (Edna, 83)

The data suggested more accounts from women carers of providing emotional support at night, and being kept awake by intrusive thoughts and worries about diverse aspects of caregiving, which were often intensely stressful.

\section{6. 'Legacy' of caregiving - longer term impacts}

The 'legacy' of caregiving refers to longer term impacts on the carers' sleep after caring ceases. This is particularly likely after intensive caregiving and care during the terminal phases of illness.

Interviewees gave accounts of guilt about the nature of the final care for their relative, which continued to disturb their sleep. This related to awareness of the pain they suffered, the undignified medical interventions they experienced, or whether the carer could (or should) have done more for them. Some recounted sleep problems due to guilt in 'putting' their relative into a residential facility. Barbara had brought her brother to live with her, and given up work to care for him.

Barbara When I look back on it, I don't know how I did it, but I did it, and then we brought him (brother) up here (to live), which was so much easier for me. But he got worse, and you never know if you are doing the right thing or not... 
He had dementia and Parkinson's Disease as well... He couldn't do anything for himself really, he couldn't even feed himself in the end...

Int. Yet, you said, interestingly, that (your sleep) carried on being difficult once he had moved into the (residential) home, what way was that?

Barbara Because I feel guilty about him being in a home. I felt I should be looking after him, and they don't look after them, of course, they can't, they can't, they can't do one-to-one, like I was doing, you know. But yes, you do feel guilty. (Barbara, 71)

Some carers reported that their sleep was disrupted for long periods after caregiving ceased by continued night-time distressing images of the final care for their 'loved one'. This was particularly associated with caregiving at the final stages of life, when their relative was undignified and vulnerable. Debora nursed her husband with cancer for 3 years before he died, and recounted that both guilt and distressing images of the final stages of care adversely affected her sleep after he died:

Debora Although I was waking up a lot then, I thought 'Oh, this will pass', you know, and you get through the funeral... and after a few months, I thought 'Oh well, my sleep isn’t coming back, like I hoped it would.'

Int. Did it improve a bit?

Debora It improved a little bit, yes, but then, of course, the things that wake you up are, when you have been through that, you are thinking 'Could I have done anything else? What about if I had done this or said that?' And you just get those 
sort of thoughts as well, that wake you up. And constant dreams, dreams, and being there. (Debora, 73)

\begin{abstract}
After caregiving ends, despite no longer experiencing sleep disturbance due to providing care at night, the sleep of interviewees often continued to be disrupted through the 'legacy' of caregiving. In Bianchera and Arber's (2007) Italian research, a third type of legacy of caregiving related to carers' feeling they may still be 'called' in the night, leading to restless and anxious sleep. However, we did not find examples of this type of legacy in the English data.
\end{abstract}

\title{
Discussion
}

Most caregiving research has hitherto focused on the physical and emotional labour of providing daytime care, neglecting the night-time and how caregiving at night may impact on carers' sleep and well-being. This paper has proposed a framework of six distinct 'aspects of caregiving' at night that can adversely affect carers' sleep, derived from analysis of indepth interviews with older men and women in England (Chart 1).

The six 'aspects of caregiving' at night which potentially affect carers' sleep were: (1), attending to the night-time physical needs of the care receiver; (2) anticipation of nighttime care needs, which may keep the carer awake or result in 'alert' or 'light' sleep; (3) the carer may engage in 'monitoring' their relative at night; (4) many frail, chronically ill 
or disabled people spend long periods of time awake at night, wander around the house, or shout, especially people with dementia; (5) emotional labour, worries or anxieties at night linked to the care recipient; and (6) the legacy of caregiving may continue to disrupt sleep long after caring ceases, with carers haunted by painful images of their relative's suffering, or feelings of guilt about not having provided adequate care.

The framework in Chart 1 extends earlier work on how Italian women's sleep was influenced by caring across the life course (Bianchera \& Arber, 2007) by adding two further aspects of night-time caregiving that disturb sleep: 'monitoring and surveillance' and 'disruptive night-time behaviours of the care recipient'. The English data showed that the other four aspects previously identified by Bianchera and Arber (2007) from research on Italian women caring for children as well as older people, were equally applicable in the different cultural and welfare context of England, and for both men as well as women caregivers. The English data illustrates each of the six aspects of nighttime caregiving, and points to the ways that location of caregiving, sleeping arrangements, reasons for caring, and gender may differentiate the effects on carers.

Care of a relative with severe disability, terminal illness or dementia often involved most of these six aspects of caregiving at night, resulting in substantial adverse effects on carers' sleep. This particularly occurred among partners caring for their spouse, although, there were examples of co-resident caregiving for parents or other relatives, which severely disrupted carers' sleep. Other studies also document the very intensive and demanding nature of spouse care (Ross et al., 2008). Co-resident carers are more likely to 
experience nightly sleep disturbance than those 'caring at a distance'. However, caring for a relative (usually a parent) who lives elsewhere may result in sleep disturbance through the anticipation of having to provide care at night (aspect 2); worries and anxieties about the care recipient (aspect 5) and the legacy of caregiving (aspect 6).

Sleeping location within the home may influence night-time caregiving activities and therefore the potential for sleep disruption. The cultural norm in England is for partners to sleep in the same bed/room, although this normative assumption relaxes somewhat after age 60 and in cases of illhealth (Hislop \& Arber, 2006; Hislop, 2007). All except one of the English spouse carers shared a bed with their partner, experiencing sleep disturbance through their partner's movements or being attuned to their partner's wellbeing during the night. However, co-sleeping facilitated 'monitoring' of their partner at night, which could provide reassurance to the carer. The one exception was Doug, whose wife had moved to sleep downstairs, which resulted in an improvement in his sleep through not being directly disturbed by his wife at night.

Gender is intricately linked to caregiving at night. Regarding spouse care, our data showed that both older men and women were heavily engaged in caring for their partners, often over lengthy periods, which resulted in substantial sleep disturbance. Although, older male spouse carers were fully involved in all aspects of night-time care, there was some suggestion that male carers were less engaged in 'sentient activities' (Mason, 1996) of providing emotional support at night than female carers. Fewer men than women talked about night-time worries and anxieties about caregiving or the care recipient 
(aspect 5). There was also a suggestion that women's sleep was more affected than men's by the legacy of caregiving, especially related to guilt (aspect 6). Further research is needed to disentangle gender differences in engagement in different 'aspects of caregiving' at night, especially regarding emotional labour, and whether women carers' night-time sleep is more disrupted than that of equivalent male carers. Hirst's (2005) prospective study showed that the risk of psychological distress increased with the intensity of care (measured by caring hours), but this risk was greater for women than men undertaking a similar number of caring hours, with distress levels elevated following the cessation of caregiving, especially for women carers.

Co-resident caregiving may extend over many years, especially spouse care, resulting in the carer having disrupted sleep for lengthy periods. There were instances in our research where various aspects of caregiving at night led to extreme stress and fatigue, which ultimately precipitated entry of their relative into a residential setting, supporting the findings of Pollak and Perlick (1991). It is timely to assess whether disturbed sleep acts as a mechanism through which caregiving leads to stress or depression among carers, as well as entry into residential care.

\section{Conclusions}

Previous literature on caregiving has largely neglected the night-time. Our proposed framework of six aspects of care provision at night can be used in future studies of 
caregiving, particularly to assess the impact on carers' sleep, day-time functioning, wellbeing and quality of life.

In societies such as England, where intensive care for a spouse (up to the end-of-life) is normative, spouses' sleep may be severely compromised for long periods, even where daytime support is provided by domiciliary carers or other family members. Co-resident care for a relative with dementia or life-limiting illness may be ongoing for several years, with carers engaged in all six aspects of caregiving at night. Even where the care recipient lives elsewhere or in a residential facility, carers' sleep may be disturbed by the anticipation of being called at night, anxiety and the legacy of caregiving.

Night-time care provision is largely invisible both to the public and to the research community. The proposed framework can be used by researchers and health professionals to assess the impact of caregiving at night, and to seek ways to minimize the adverse effects of night-time caregiving on carers' sleep and well-being. A key goal should be to assess whether compromised sleep is a causal factor in caregiver stress, burnout and depression, as well as precipitating residential admission. 


\section{Acknowledgements}

The SomnIA (Sleep in Aging) research was funded by the New Dynamics of Aging initiative, a multidisciplinary research programme supported by AHRC, BBSRC, EPSRC, ESRC and MRC (RES-339-25-0009). We are grateful to Rebekah Luff, Rob Meadows and Tony Warnes for their helpful comments on an earlier version of this paper, and for support from other colleagues on the SomnIA project. 


\section{References}

Arber, S., Hislop, J., Bote, M. \& Meadows, R., (2007). Gender roles and women's sleep in mid and later life: a quantitative approach. Sociological Research Online, 12, 5, http://www.socresonline.org.uk/12/5/3.html.

Arber, S., Bote, M., \& Meadows, R. (2009). Understanding how socio-economic status, gender and marital status influence self-reported sleep problems in Britain. Social Science and Medicine, 68, 281-289.

Askham., J., Briggs, K., Norman, I ., \& Redfern, S. (2007). Care at home for people with dementia: as in a total institution? Aging and Society, 27, 1, 3-24.

Ayas, N.T., White, D.P., Al-Delaimy, W.K., Manson, J., Stampfer, M., Speizer, F., Patel, S., \& Hu, F. (2003). A prospective study of reported sleep duration and incident diabetes in women. Diabetes Care, 26, 380-384.

Beaudreau, S.A., Spira, A.P., Gray, H.L., Depp, C.A., Long, J., Rothkopf, M., \& Gallagher-Thompson, D. (2008). The relationship between objectively measured sleep disturbance and dementia family caregiver distress and burden. Journal of Geriatric Psychiatry and Neurology, 21, 3, 159-165.

Bianchera, E., \& Arber, S. (2007). Caring and sleep disruption among women in Italy. Sociological Research Online, 12(5) http://www.socresonline.org.uk/12/5/4.html. 
Bliwise, D.L. (1993). Sleep in normal aging and dementia - a review. Sleep, 16, 40-81.

Bond, M.J., Clark, M.S. \& Davies, S. (2003). The quality of life of spouse dementia caregivers: changes associated with yielding to formal care and widowhood. Social Science and Medicine, 15, 2, 2385-2395.

Buysse D.J., Reynolds C.F., Monk T.H., Berman S.R., \& Kupfer D.J. (1989). The Pittsburgh Sleep Quality Index: A new instrument for psychiatric practice and research. Psychiatry Research, 28, 2, 193-213.

Cannuscio, C.C., Jones, C., Kawachi, I., Colditiz, G.A., Berkman, L., \& Rimm, E. (2002). Reverberations of family illness: A longitudinal assessment of informal caregiving and mental health status in the Nurses' Health Study. American Journal of Public Health, 92, 8, 1305-11.

Carter, P.A., \& Chang, B. (2000). Sleep and depression in cancer caregivers. Cancer Nursing, 23, 6, 410-5.

Creese, J., Bedard, M., Brazil, K., \& Chambers, L. (2006). Sleep disturbance in spousal caregivers of individuals with Alzheimer's disease. American Journal of Geriatric Psychiatry, 14, 2, 112-20. 
Dahlberg, L., Demack, S., \& Bambra, C. (2007). Age and gender of informal carers: a population-based study in the UK. Health and Social Care in the Commuity, 15, 5, 43945.

Davidson, J.R., MacLean, A.W., Brundage, M.D., \& Schulze, K. (2002). Sleep disturbance in cancer patients. Social Science \& Medicine, 54, 1309-1321.

Ferrie, J.E., Shipley, M.J., Cappuccio, M.D., Brunner, E., Miller, M.A. Kumari, M., \& Marmot, M.G. (2007). A prospective study of change in sleep duration: Associations with mortality in the Whitehall II cohort. SLEEP, 30, 12, 1659-66.

Finch, J., \& Groves, D. (1983). A Labour of Love: Women, Work and Caring. Routledge and Kegan Paul, London.

Happe, S., \& Berger, K. (2002). The association between caregiver burden and sleep disturbance in partners of patients with Parkinson's disease. Age and Aging, 31, 34954.

Hartz, A.J., Daly, J.M., Kohatsu, N.D., Stromquist, A.M., Jogerst, G.J., \& Kukoyi, O.A. (2007). Risk factors for insomnia in a rural population. Annals of Epidemiology, 17, 940947. 
Heslop, P., Smith, G.D., Metcalfe, C., Macleod, J., \& Hart, C. (2002). Sleep Duration and Mortality: The Effect of Short or Long Sleep Duration on Cardiovascular and All-cause Mortality in Working Men and Women. Sleep Medicine, 3, 4, 305-14.

Hirst, M. (2005). Carer distress: A prospective, population-based study. Social Science and Medicine, 61, 697-708.

Hislop, J., \& Arber, S. (2006). 'Sleep, gender and aging: Temporal perspectives in the mid-to-later life transition'. In T. Calasanti \& K. Slevin (eds) Age Matters: Realigning Feminist Thinking, Routledge, London.

Hislop, J. (2007). A bed of roses or a bed of thorns? Negotiating the couple relationship through sleep. Sociological Research Online, 12, 5. http://www.socresonline.org.uk/12/5/2.html.

James, N. (1992). Care $=$ organisation + physical labour + emotional labour, Sociology of Health and Illness, 14, 4, 488-509.

Keene, J.R., \& Prokos, A.H. (2008). Widowhood and the end of spousal caregiving: relief of wear and tear? Aging and Society, 28, 4, 551-570. 
Kesselring, A., Krulik, T., Bichsel, M. et al. (2001). Emotional and physical demands on caregivers in home care to the elderly in Switzerland and their relationship to nursing home admission. European Journal of Public Health, 11, 267-73.

Lawrence, J.A., Goodnow, J.J., Woods, K., \& Karantzas, G. (2002). Distributions of caregiving tasks among family members: the place of gender and availability. Journal of Family Psychology, 16, 4, 493-509.

Lee, D., Morgan. K., \& Lindesay, J. (2007). Effect of institutional respite care on the sleep of people with dementia and their primary caregivers. Journal of American Geriatrics Society, 55, 252-8.

Maher, J., \& Green, H. (2002). Carers 2000. National Statistics, The Stationery Office, London.

Miles, M., \& Hurberman, M. (1994). Qualitative Data Analysis: an expanded sourcebook, Beverley Hills, London,

Neysmith, S.M., \& Reitsma-Smith, M. (2009). The provisioning responsibilities of older women. Journal of Aging Studies, 23, 236-244.

Pollak, C.P., \& Perlick, D. (1991). Sleep problems and the institutionalization of the elderly. Journal of Geriatric Psychiatry and Neurology, 4, 4, 204-10. 
Riedel, B.W., \& Lichstein, K.L. (2000). Insomnia and daytime functioning. Sleep Medicine Review, 4, 277-98.

Rosenthal, C.J., Martin-Matthews, A., \& Keefe, J.M. (2007). Care management and care provision for older relatives amongst employed informal caregivers. Aging and Society, $27,5,755-78$.

Ross, A., Lloyd, J., Weinhardt, M., \& Cheshire, H. (2008). Living and Caring? An Investigation of the Experiences of Older Carers. International Longevity Centre - UK, London.

Sims-Gould, J., Martin-Matthews, A., \& Rosenthal, C.J. (2008). Family caregiving and helping at the intersection of gender and kinship. In A. Martin-Matthews \& J. Phillips (eds) Aging and Caring at the Intersection of Work and Home Life, Taylor and Francis, New York.

Smith, M.C., Ellgring, H., \& Oertel, W.H. (1997). Sleep disturbances in Parkinson’s disease patients and spouses. Journal of the American Geriatrics Society, 45, 2, 194-9.

Spiegel, K., Leproult, R., \& Van Cauter, E. (1999). Impact of sleep debt on metabolic and endocrine function. Lancet, 354, 1435-9. 
Van Someren, E.J.W. (2000). Circadian sleep disturbances in the elderly. Experimental Gerontology, 35, 1229-37.

Ustun, T.B. (2000). Cross-national epidemiology of depression and gender. Journal of Gender Specific Medicine, 3, 54-8.

Vitiello, M.V., Moe, K.E., \& Prinz, P.N. (2002). Sleep complaints cosegregate with illness in older adults. Clinical research informed by and informing epidemiological studies of sleep. Journal of Psychosomatic Research, 53, 555-559.

Wilcox, S.,\& King, A.C. (1999). Sleep complaints in older women who are family caregivers. Journal of Gerontology: Physiological Sciences, 54B, 3, 189-198.

Williams, S. (2005). Sleep and Society: Sociological Ventures into the (Un)known, Routledge, London.

Zarit, S.H., Reever, K.E., \& Bach-Peterson, J. (1980). Relatives of the impaired elderly: correlates of feelings of burden. The Gerontologist, 20, 649-655. 


\begin{tabular}{|c|c|c|c|c|c|}
\hline & Gender of carer & $\begin{array}{c}\text { Age } \\
\text { of } \\
\text { carer }\end{array}$ & $\begin{array}{c}\text { Relationship } \\
\text { to care } \\
\text { recipient }\end{array}$ & $\begin{array}{l}\text { Location of } \\
\text { caregiving }\end{array}$ & $\begin{array}{l}\text { Reason for } \\
\text { caregiving }\end{array}$ \\
\hline \multicolumn{6}{|c|}{ Relationship to carer: Partner } \\
\hline 1. & Male & 76 & Wife & Carer's Home & Cancer \\
\hline 2. & Female & 73 & Husband & Carer's Home & Stroke \\
\hline 3. & Male & 67 & Wife & Carer's Home & Cancer \\
\hline 4. & Male & 80 & Wife & Carer's Home & Heart/arthritis \\
\hline 5. & Female & 71 & Husband & Carer's Home & Stroke \\
\hline 6. & Male & 82 & Wife & Carer's Home & Cancer \\
\hline 7. & Female & 83 & Husband & Carer's Home & Chronic joint pain \\
\hline 8. & Female & 67 & Husband & $\begin{array}{l}\text { 1. Carer's Home } \\
\text { 2. Care home }\end{array}$ & Alzheimer's disease \\
\hline 9. & Male & 75 & $\begin{array}{l}\text { Wife (1) } \\
\text { Wife (2) }\end{array}$ & $\begin{array}{l}\text { Carer's Home } \\
\text { Carer's Home }\end{array}$ & $\begin{array}{l}\text { Unspecified } \\
\text { Unspecified }\end{array}$ \\
\hline \multicolumn{6}{|c|}{ Relationship to carer: Other family members } \\
\hline 10. & Male & 81 & Brother & Own home & $\begin{array}{l}\text { Multiple } \\
\text { disabilities/age }\end{array}$ \\
\hline 11. & Female & 72 & Mother & Carer's home & $\begin{array}{l}\text { Respiratory/multiple } \\
\text { disabilities }\end{array}$ \\
\hline 12. & Female & 72 & Mother & Carer's home & Age \\
\hline 13. & Female & 71 & Mother & Own home & Unspecified \\
\hline 14. & Female & 71 & Brother & $\begin{array}{l}\text { 1. Carer's home } \\
\text { 2. Care home }\end{array}$ & Dementia \\
\hline 15. & Female & 67 & Daughter & Carer's home & Depression \\
\hline 16. & Female & 78 & Partner of son & Carer's home & Depression \\
\hline 17. & Male & 76 & Mother & Carer's home & Unspecified \\
\hline 18. & Female & 79 & Mother & Own home & Alzheimers disease \\
\hline
\end{tabular}




\begin{tabular}{|r|l|l|l|l|l|}
\hline \multicolumn{2}{|l|}{ Relationship to carer: Multiple recipients of care } \\
\hline 19. & Female & 79 & $\begin{array}{l}\text { Husband } \\
\text { Mother }\end{array}$ & $\begin{array}{l}\text { Carer's Home } \\
\text { Carer's Home }\end{array}$ & $\begin{array}{l}\text { Heart } \\
\text { Multiple } \\
\text { disabilities/age }\end{array}$ \\
\hline 20. & Male & 76 & $\begin{array}{l}\text { Mother } \\
\text { Mother-in-law }\end{array}$ & $\begin{array}{l}\text { Carer's Home } \\
\text { Carer's Home }\end{array}$ & $\begin{array}{l}\text { Unspecified } \\
\text { Unspecified }\end{array}$ \\
\hline 21. & Female & 72 & $\begin{array}{l}\text { Mother } \\
\text { Father }\end{array}$ & $\begin{array}{l}\text { Carer's Home } \\
\text { Carer's Home }\end{array}$ & $\begin{array}{l}\text { Dementia } \\
\text { Cancer }\end{array}$ \\
\hline 22. & Male & 65 & $\begin{array}{l}\text { Mother-in-law } \\
\text { Father-in-law }\end{array}$ & $\begin{array}{l}\text { Hospital } \\
\text { Hospital }\end{array}$ & $\begin{array}{l}\text { Cancer } \\
\text { Dementia }\end{array}$ \\
\hline 23. & Female & 71 & $\begin{array}{l}\text { Mother } \\
\text { Father } \\
\text { Husband }\end{array}$ & $\begin{array}{l}\text { Carer's Home } \\
\text { Carer's Home } \\
\text { Carer's Home }\end{array}$ & $\begin{array}{l}\text { Alzheimers } \\
\text { Unspecified } \\
\text { Heart }\end{array}$ \\
\hline Legacy of work involving care & 65 & $\begin{array}{l}\text { Manager of } \\
\text { older people's } \\
\text { care provision } \\
\text { company }\end{array}$ & Own homes & $\begin{array}{l}\text { Fear of clients not } \\
\text { receiving appropriate } \\
\text { care }\end{array}$ \\
\hline 24. & Female & $\begin{array}{l}\text { Social worker } \\
\text { care of } \\
\text { young people }\end{array}$ & Own homes & $\begin{array}{l}\text { Concerns for young } \\
\text { people on his list }\end{array}$ \\
\hline 25. & Male & 78 &
\end{tabular}

Table 1: Characteristics of carer's and care recipients 
1. Providing direct physical care at night - tending, toileting, etc., results in sleep disruption, but the impact depends on how easily the carer can fall back to sleep afterwards.

2. Anticipation of having to provide night-time care - results in light, alert sleep and non restorative sleep.

3. Monitoring and surveillance - the carer gets up at frequent intervals to 'check on' the care receiver.

4. Wandering and disruptive night-time behaviours of the care recipient - the care recipient goes to bed very late, gets up in the middle of the night, wanders round the house, shouts or makes other noises during the night, which disturb the carers' sleep.

5. Emotional labour and worries about the care recipient - which includes:

- Providing emotional support at night

- Generalized or short-term worries about the care recipient, e.g. are they in pain, are they sleeping, will they fall out of bed

- Long-term worries - e.g. will husband have to 'be put in' an institution.

6. 'Legacy' of caregiving - can potentially disrupt sleep after care provision ceases:

- Feelings of guilt - that they should have done more, e.g. not put relative in a residential facility

- Continued distressing images of their 'loved one' in pain, suffering - flashbacks

- Carers feel they may still be 'called' in the night, resulting in light sleep.

\section{Chart 1. Framework of how aspects of caregiving at night influence carers' sleep}




\title{
Appendix A: Interview Topic Guide
}

\section{Understanding sleep amongst older people}

\author{
Interview Topic Guide
}

Ask the participant to tell us in a general way about their sleep.

Raise the following topics, if not covered above.

- What constitutes a good night's sleep

- What is a poor night's sleep like

- How does poor sleep make them feel

- How does poor sleep impact on their day to day activities

- How has their sleep changed

- Does their sleep impact on their partners/family members, and if so how

- Do partners/family members impact on their sleep, and if so why?

- Contributing factors for poor sleep, such as stress/worry (eg bereavement, financial concerns) and physical factors (poor health, pain, getting up to the toilet, leg cramps etc)

- other historical/current factors such as care giving for other relatives - in particular have they lost sleep over getting up for older parents/relatives (parents/relatives/children etc)

Questions relating to coping strategies for poor sleep:

- Sleep medications (prescribed/over the counter/alternative therapy)

- Strategies for dealing with difficulty getting to sleep

- Strategies for coping with waking in the night

- Difficulty getting up in the morning

- Seeking help for difficulty sleeping (eg doctor/chemist)

- Napping - perception of and relationship to, ie blame, guilt, planned napping, plus probe for unplanned sleep, dozing - is there a difference in the perception of napping/dozing

- Routines, such as listening to the radio, having a snack prior to bed

- Questions about their sleeping environment and whether they have made adjustments to these to help with sleep:

- Layout of bedroom

- Bed

- Lighting

- Pillows

- Windows

- Side of bed 
Identifying whether aspects of daily living such as light exposure, physical activity and food are associated with poor sleep:

- Questions on daily activity levels, such as going shopping/gardening/housework

- How much time spent outside

- Food consumption - including buying groceries/preparing food/cooking meals and cleaning up

- Alcohol, tobacco and caffeine consumption

Do participants have any medical/health conditions or disabilities and how these impact on sleep:

- What medications are routinely taken on a daily basis

- If medication is taken, what they perceive is its impact on their sleep

- What are respondents' experiences of, and attitudes to, taking sleeping medication

Anything else to add about their sleep and why they decided to take part in the study.

Final question, is sleep important to you, and if so why? 